\title{
Marble pneumoconiosis associated with mixed connective tissue disease
}

\author{
Alexander P Rozin* and Kohava Toledano \\ ${ }^{*}$ Correspondence: a_rozin@rambam.health.gov.il \\ B. Shine Department of Rheumatology, Rambam Health Care Campus and Technion, Haifa, Israel.
}

\begin{abstract}
Caplan's syndrome: combination of pneumoconiosis and lung nodes due to seropositive rheumatoid arthritis (RA) is well known entity. We present 45 years old marble worker with fever, cough, and exertion dyspnoe with multiple lung nodes, infiltrates and fibrosis by chest CT and Raynaud syndrome with vascular finger tip lesions. Our patient had 7 years history of mixed connective tissue disease. Skin vascular lesions rapidly regressed after nifedipine therapy and methylprednisolone pulses. Substantial response of the lung disease to steroid and antibiotic therapy was not observed. Due to further respiratory failure the patient was underwent lung transplantation. Histology from removed lung showed dust laden macrophages with weak polarization positivity, advanced silicotic nodules with focal calcifications surrounded by chronic inflammation and massive fibrosis. No acid fast bacteria were found. Above mentioned findings extend a field of Caplan's syndrome. Different dusts and other rheumatic diseases, a part from RA, might be implicated.
\end{abstract}

Keywords: Marble pneumoconiosis, mixed connective tissue disease, vasculitis, Caplan's syndrome

\section{Introduction}

We are all acquainted with well known entity known as Caplan's syndrome, a combination of pneumoconiosis and lung nodes due to seropositive rheumatoid arthritis (RA). Ninety percent of coal miners with RA had a nodular interstitial lung disease (ILD) as compared with $30 \%$ of coal miners with ILD without RA [1] and $0.4 \%$ in RA patients without exposure to coal dust [2]. In $25 \%$ of patients with Caplan's syndrome the opacities were multiple, round, well defined, and distributed fairly evenly throughout both lung fields, predominantly at the periphery.

\section{Case presentation}

We present a 45 years old marble worker (15 years exposure) with fever, cough, and exertional dyspnea with multiple lung nodes, infiltrates and fibrosis on chest CT (Figure 1). Our patient had a 7 year history of polyarthritis as part of a mixed connective tissue disease (RA, SLE, Sjogrene) with positive serology: RF, ANA, RNP, SSA, SSB, polyclonal hypergammaglobulinemia, ANCA negative and with good response of the arthritis, polycytopenia and Raynaud's phenomenon to hydroxychloroquine and prednisone therapy. His lung disease was not associated with constitutional symptoms and respiratory disability for an extended period of time. Physical examination showed Raynaud's phenomenon, multiple finger tip ischemic and necrotic lesions (Figure 2) and bilateral end-inspiratory crackles. Several lymph node biopsies from mediastinal and abdominal region revealed granulomatous necrotizing inflammation without acid fast bacilli. Peripheral finger infarcts indicated the vascular nature of MCTD. Vascular lesions regressed rapidly after nifedipine therapy and methylprednisolone pulses. Spirometry showed severe restrictive disease. Substantial response of the lung disease to steroid and antibiotic therapy was not observed. Due to progressive respiratory failure the patient underwent lung transplantation. Histology from removed lung showed dust laden macrophages with weak polarization positivity, advanced silicotic nodules (Figure 3) with focal calcifications surrounded by chronic inflammation as well as massive fibrosis. No acid fast bacteria were found.

\section{Discussion}

Exposure to marble dust has recently been reported as a risk factor for lung silicosis [3]. MCTD has previously been reported in association with silicosis following intentional scouring powder inhalation [4]. This collagen disease developed 5 years after diagnosis of acute silicosis. The scouring powder silicosis was also associated with vasculitic sequelae [5]. Above mentioned findings extend the field of Caplan's disease to include marble pneumoconiosis and MCTD. Different dusts and other rheumatic diseases, apart from RA, might also be implicated. Persons with exposure to dusts should be investigated early due to the long subclinical period found in marble pneumoconiosis. Patients with lung disease should be interviewed with meticulous occupation history taking.

\section{Competing interests}

The authors declare that they have no competing interests.

\section{Publication history}

Received: 24-Apr-2013 Revised: 09-May-2013

Accepted: 11-Jun-2013 Published: 18-Jun-2013 


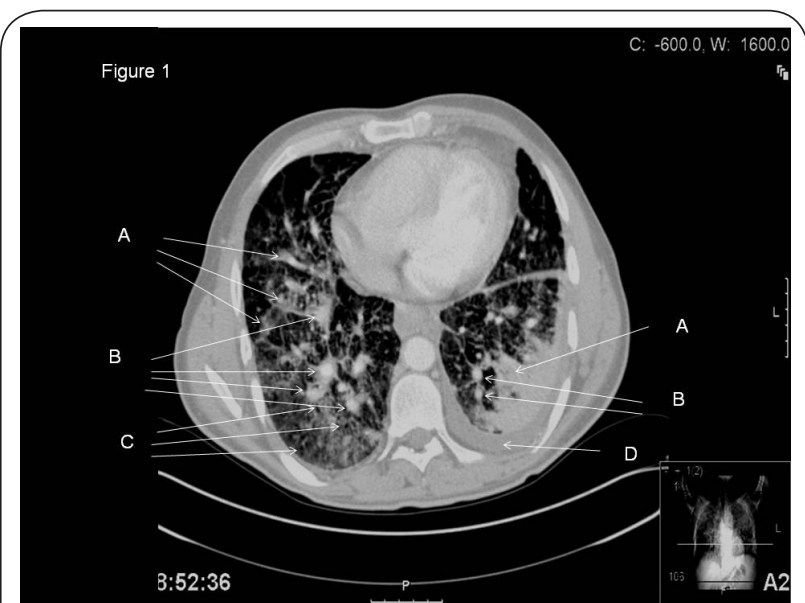

Figure 1. Chest CT shows patchy interstitial infiltrates with fibrosis (A), lung nodes (B), small cystic radiolucencies honeycombing (C) and left pleural effusion (D).

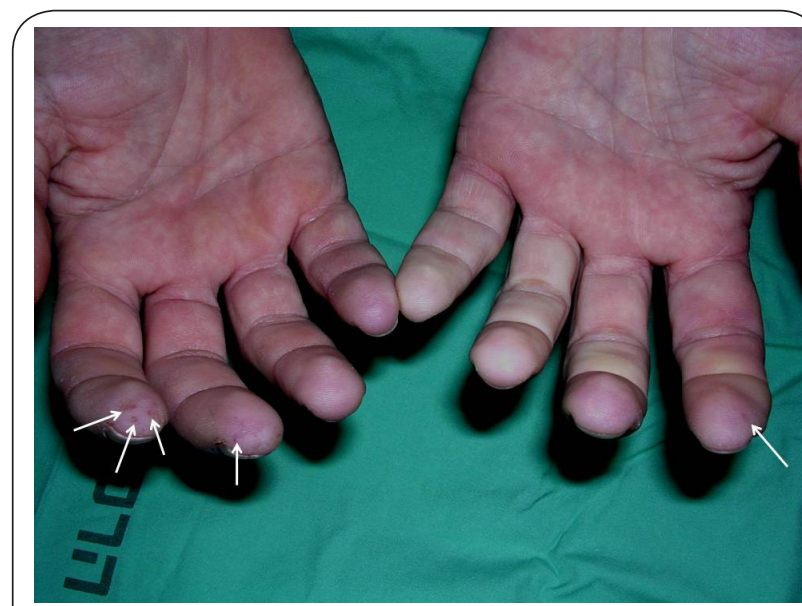

Figure 2. Multiple finger tip ischemic lesions are seen along with active Raynaud's phenomena - mixed connective tissue disease vasculitis.

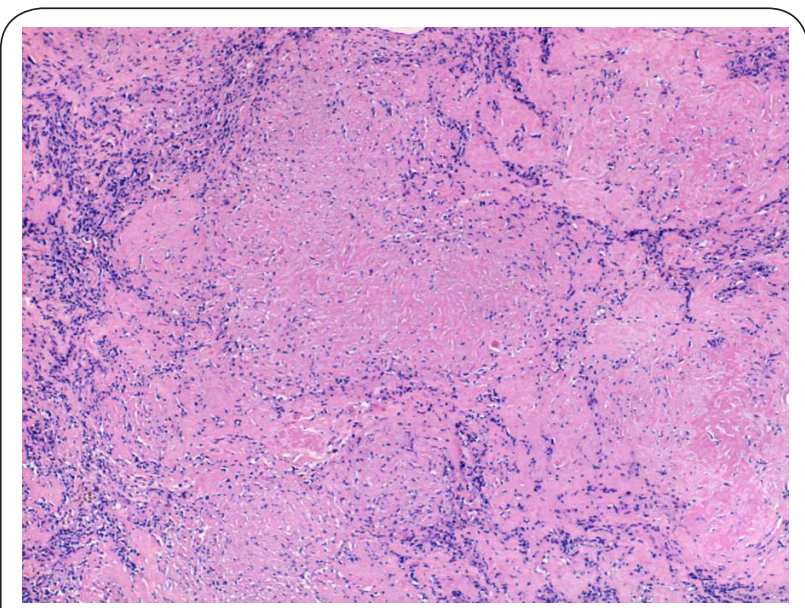

Figure 3. A silicotic hialinizing nodule from mediastinal lymph node is seen. It is composed mainly of bundles of interlacing pink collagen with mild inflammatory reaction. Silicotic nodule formation is responsible for development of restrictive lung disease. Hematoxylin\&eosin. X100.

\section{References}

1. Caplan A: Certain unusual radiological appearances in the chest of coal-miners suffering from rheumatoid arthritis. Thorax 1953, 8:29-37. | Article | PubMed Abstract | PubMed Full Text

2. Walker WC and Wright V: Pulmonary lesions and rheumatoid arthritis. Medicine (Baltimore) 1968, 47:501-20. | Article | PubMed

3. Leikin E, Zickel-Shalom K, Balabir-Gurman A, Goralnik L and Valdovsky $\mathrm{E}$ : [Caplan's syndrome in marble workers as occupational disease]. Harefuah 2009, 148:524-6, 572. | PubMed

4. Vincent M, Pouchelle C, Martinon S, Gerard F and Arthaud Y: Connective tissue disease due to intentional inhalation of scouring powder. Eur Respir J 1996, 9:2688-90. | Article | PubMed

5. Gong $\mathrm{H} \mathrm{Jr}$ and Tashkin DP: Silicosis due to intentional inhalation of abrasive scouring powder. Case report with long-term survival and vasculitic sequelae. Am J Med 1979, 67:358-62. | PubMed

\section{Citation:}

Rozin AP and Toledano K: Marble pneumoconiosis associated with mixed connective tissue disease. Intern Med Inside 2013, 1:6.

http://dx.doi.org/10.7243/2052-6954-1-6 